\title{
Science, technology and sustainable development
}

The fundamental importance of science and technology in both socio-economic and cultural development is now recognized and accepted without doubt the world over. However, it is important to keep in mind that economic growth and infrastructure development can also potentially bring about undesirable changes in the environment and depletion of the natural resources which would lead to an unsustainable situation. It is the responsibility of all stakeholders, in particular the scientists and technologists, to develop and maintain systems that would ensure sustainable development and quality life of our future generations.

The scientific and technological community represented by the International Council of Science (ICSU) and the World Federation of Engineering Organizations (WFEO) jointly presented their views on this matter to the World Summit on Sustainable Development (WSSD) held in Johannesburg in 2002. Ramasamy in a presentation titled Science and Technology for Sustainable Development made at the Sri Lanka Association for the Advancement of Science (SLAAS) Theme Seminar, Sustainable Development: Key to National Progress, during its Annual Session in 2002, had reported the following as key issues identified by the world community of scientists and engineers at this summit.

These were: A new contract between scientists, technologists and society; Reorienting research priorities with increased support from society/government for research; Building and maintaining S\&T capacity; Innovation of appropriate new technologies; and S\&T expertise in government.

He has also elaborated as follows. Addressing social equity, poverty reduction and other social needs must become integral to S\&T endeavours which need a reorientation of the thinking of scientists, technologists, research funding agencies, universities, research institutes and the government. Science and engineering must give higher priority to identify solutions for pressing development challenges with enhanced support by society and the government requiring the identification of problems that are amenable to solutions through S\&T, prioritizing the problems to be addressed in terms of the output expected from the expended effort and much greater appreciation by the government and the Treasury on the issues involved, resulting in a corresponding increase in government investment on S\&T. The responsibility of building and maintaining S\&T capacity through creating and sustaining an attractive environment with the necessary working infrastructure, a just and fair recognition for output, rational administration and satisfactory remuneration lies with the government, while the scientists and technologists should take the responsibility of communicating the scope and significance of their work to the public at large. Development and sharing of new and existing technologies must be encouraged and directed towards sustainable production and consumption patterns. Responsible engagement of the S\&T community in the decision making process is indispensable for effective governance aimed at sustainable development.

These views expressed in 2002 are still valid to a great extent even today despite efforts by the relevant authorities to address the issues over the years.

The shift to collaborative research among scientists, engineers and social scientists has been attempted by funding agencies such as the National Science Foundation. However, the interest shown by scientists to undertake such research projects is inadequate and methodologies to create greater interest among the scientists need to be developed. Some of the pressing problems in various sectors that need scientific investigations too remain unsolved. This is partly due to the lack of appreciation in the past by the authorities that such problems if researched scientifically will provide essential information for their solution. The authorities need to take the initiative to involve scientists and provide adequate funding for research to find solutions to national level problems. It is encouraging to note that the government has now 
accepted that application of science and technology and the promotion of research are essential for economic development and therefore set an investment target of $1 \%$ of GDP for research. This will give new meaning and possibilities for the building and maintenance of science and technology capacity towards national development when the target is achieved.

Scientists and technologists have to play a key role in communicating to the government and disseminating to society the importance and relevance of the on-going scientific effort. Both government and the public must be informed about the nature and impact of key scientific and technological developments. The scientists and science and technological institutions will find this an easy task if they team up with science journalists. Cooperation between them will enable the communication of the scope and the significance of their achievement to the public at large in all national languages.
Another important aspect in achieving sustainable development is innovation, transfer and assimilation of appropriate technologies with minimum adverse impact on the environment. Technologies to be transferred have to be adapted to suit local conditions and this needs the support of scientists and engineers. The responsibility of the researchers goes well beyond research results leading to new technologies. It is crucial for the development of the country that these researchers develop the technologies to the level where they can be commercialized and used by local entrepreneurs.

The role of scientists and technologies in sustainable development of the country also includes their responsible engagement in the decision making processes at all levels of governance. The existing mechanisms to enable this are inadequate and the scientists and technologists will have to work with the government to find the solution.

Nalini Ratnasiri 